\title{
Distributed Generation Harmonic Interaction in the Active Distribution Network
}

\author{
Marko VUKOBRATOVIĆ, Predrag MARIĆ, Srete NIKOLOVSKI, Hrvoje GLAVAŠ
}

\begin{abstract}
Significant increase of distributed generation (DG) presence and active distribution network (ADN) development cause changes in distribution network's power quality (PQ), mostly in distorted system voltages and currents. This paper analyses harmonics generation from multiple DG types, such as solar and biogas power plants, and simulates harmonic interactions in ADN in order to identify potential PQ issues. Each harmonic source observed in this paper was modelled according to IEC 61000 with the model parameters provided by power quality measurements in the real system on several DG power plants and passive consumer nodes. A harmonic load flow is performed on a detailed ADN model for different presumed DG expansion scenarios that indicate the complexity of the DG impact on the AND's PQ. Quantitative and qualitative graphical presentation for cumulative and the most significant ADN nodes is given and the assessment for the potential ADN development based on PQ indices is proposed.
\end{abstract}

Keywords: active distribution network; harmonic interaction; harmonic sources; total harmonic distortion

\section{INTRODUCTION}

Distributed generation (DG) implies power plants connected to a distribution network [1] regardless of the type, size and power plant technology. In a conventional operating mode, a distribution network plays a passive role, i.e. it supplies power from the superior grid to the consumers. However, the DG emergence has changed that paradigm making the distribution network active consequently allowing power evacuation to higher voltage levels. It also includes a range of potential challenges for a distribution system operator (DSO), such as network reinforcement issues, energy balance and a possible increase of energy losses, ancillary services, cost and feasibility concerns, etc. [2-6].

The Power Quality (PQ) issue of the active distribution network (ADN) with multiple DG units has been identified by Arghandeh et al. [7]. The authors propose a new index of phasor harmonics (IPH) in order to determine harmonic interactions of multiple various types of DG considering phase angles and harmonic magnitudes. Taking into account those considerations and respecting the problem identification, this paper analyses the PQ characteristics of an ADN with a significant share of $\mathrm{DG}$ based on photovoltaic (PV) power plants and biogas based synchronous machines (SM). In order to determine the particular harmonic influence of various DG types, PQ measurements have been conducted at the Point of Common Coupling (PCC) for three PV power plants and three biogas power plants. Additionally, PQ measurements were conducted on multiple consumer nodes in order to determine the total harmonic distortion (THD) of the passive distribution network (PDN) before DG implementation. Based on the measurement data obtained and the harmonic generation of DG identified, expansion scenarios are assumed, simulations were made and the analysis of PQ in a completely active distribution network is performed. A precise PQ characteristic generated from the inverter-based PV DG is elaborated in this paper. Nominal and marginal operating conditions of various types of power plants are considered while evaluating PQ of an active distribution network.

The expected PV power plants influence on PQ in a distribution network is significant, as presented in the papers [8-13], with harmonic evaluations and influences observed. THD is taken as the relevant and the most common PQ index since it has an influence on the peak currents and grid losses [14].

Finally, conclusions are made considering the active distribution network development and DG increased share in the system.

\section{POWER QUALITY AND HARMONICS IN THE DISTRIBUTION NETWORK}

Power quality can be described as the measure of the bus voltage to maintain an invariable sinusoidal waveform at the rated voltage and frequency [15]. A deviation from a sinusoidal waveform is defined as a harmonic or waveform distortion and it is caused by harmonic components containing periodic sinusoidal waveforms with frequencies that are integer multiples of the observed system fundamental frequency [12]. Such waveforms are the result of nonlinear loads, inverters, power electronics equipment, switch-mode power supplies, etc. [15-17]. Harmonic influence can be manifested by control equipment malfunction, losses increase in transformers and rotating machines or even voltage raise caused by parallel and series resonance [15]. A periodic signal that is basically a sinusoidal waveform, but is superimposed by its multiples signals of different amplitudes, can be described by a Fourier equation [18]:

$v(t)=\sum_{n=0}^{N} V_{n} \sin \left(n \omega_{0} t+\varphi_{n}\right)$

where $v(t)$ is the instantaneous voltage at time $t, V_{n}$ is the voltage amplitude of harmonic $n, \varphi_{n}$ is the phase angle of harmonic $n, \omega_{0}$ is the fundamental frequency $(50 \mathrm{~Hz}$ for the observed power system), $n$ is the harmonic order and $N$ is the total number of harmonics in the system or the observed harmonics. The instantaneous voltage curve in the observed bus deviates from an ideal sinusoidal shape. The use of the same nomenclature, while covering the EN 50160 [14] guidelines, can be described by [19] for phase $1\left(V_{1}\right)$ : 
$V_{1}(t)=\operatorname{Re} \cdot \sum_{n=1}^{40} \sqrt{2} V_{n} \mathrm{e}^{(n \omega t+\varphi n)}$

A distortion of curve $V_{1}$ can be expressed by a wellknown and important THD index which is commonly used for PQ description [14]:

$T H D=\sqrt{\sum_{n=2}^{40}\left(v_{n}\right)^{2}}$

In the passive distribution network, the voltage curve is not shaped as an ideal sinusoid due to nonlinear consumers, static converters or large distortion sources such as furnace [15]. Additionally, unpredictable or unscheduled events, such as lightning surge propagations, faults, voltage dips, spikes, transient overvoltage and interruptions at the utility side, power electronic based loads, adjustable speed drives, highly inductive loads, transients during switching or general misapplication of technology on the customer side, contribute to the PQ decline. Aforementioned statement can be confirmed by simple PQ measuring with a Power Quality Analyser of class "A" which was carried out for the purpose of this research. The market leading PQ analyser used for this research has the possibility of recording the harmonics from 1 st to 50th according to IEC 61000-4-7 with voltage and current harmonics resolution of $0,1 \%$ and the accuracy of $\pm 0,1 \% \pm n \times 0,1 \%$. Absolute voltage measurement range is $0,0 \mathrm{~V}$ to $1000 \mathrm{~V}$ with the resolution of $0,1 \mathrm{~V}$ and accuracy of $\pm 5 \%$. Absolute current measurement range is $0,0 \mathrm{~A}$ to $600 \mathrm{~A}$ with the resolution of $0,1 \mathrm{~A}$ and accuracy of $\pm 5 \%$. Voltage and current THD resolution for the analyser used is $0,1 \%$ with the accuracy of $\pm 2 \%$.

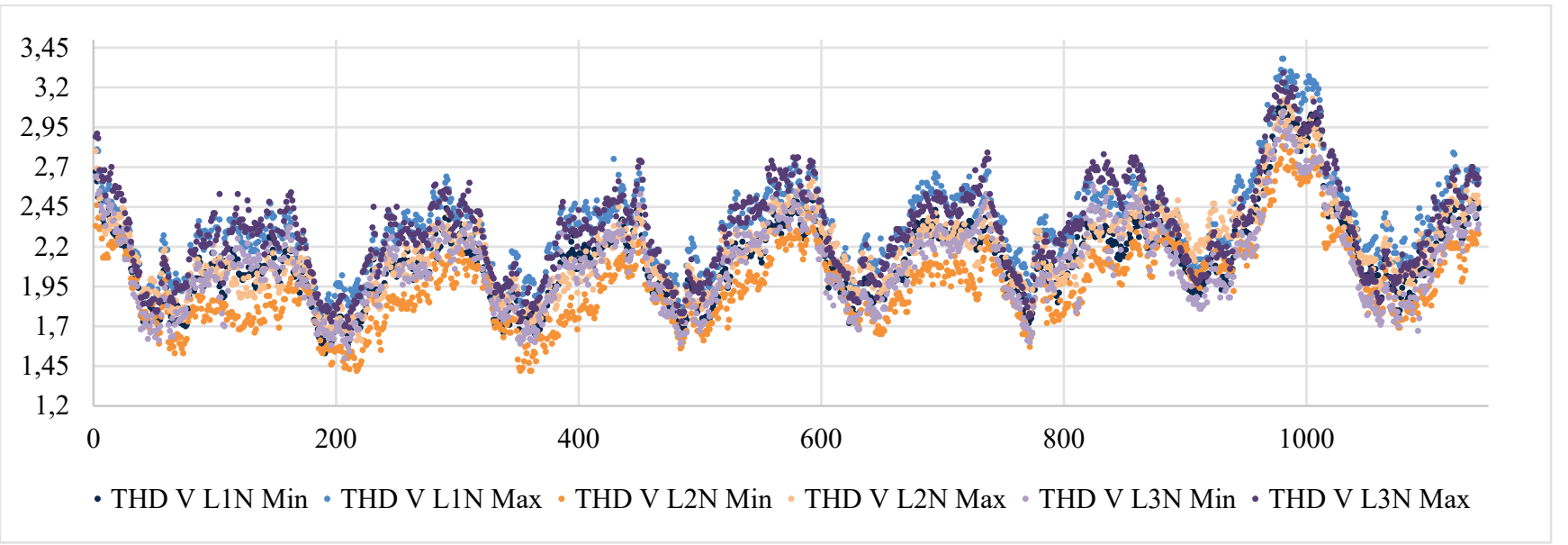

Figure $1 \mathrm{THD}$ results for the passive distribution network - Measurement 1

The results of the PQ measurements in an 8 day period, for a typical residential passive distribution network in Croatia, for a consumer node in typical household, are presented in Fig. 1. with a 10-minute values. The maximum THD of 3,38\% at the time of 3:23PM is evident. According to EN 50160, the THD of supply voltage has to be less than or equal to $8 \%$ [14]. The harmonic measurements were carried out in an 8-day period thus meeting the EN 50160 requirements for the observation period, with a 10-minute recording interval resulting in 1142 harmonic samples. The average THD value in the observed period was $2,16 \%$ with the minimal value of $1,42 \%$ early in the mornings. Harmonics that were identified as dominating were the $5^{\text {th }}$ with the average value of $1,7 \%, 7^{\text {th }}$ with the average value of $1,3 \%$ and $3^{\text {rd }}$ with the average value of $0,48 \%$.

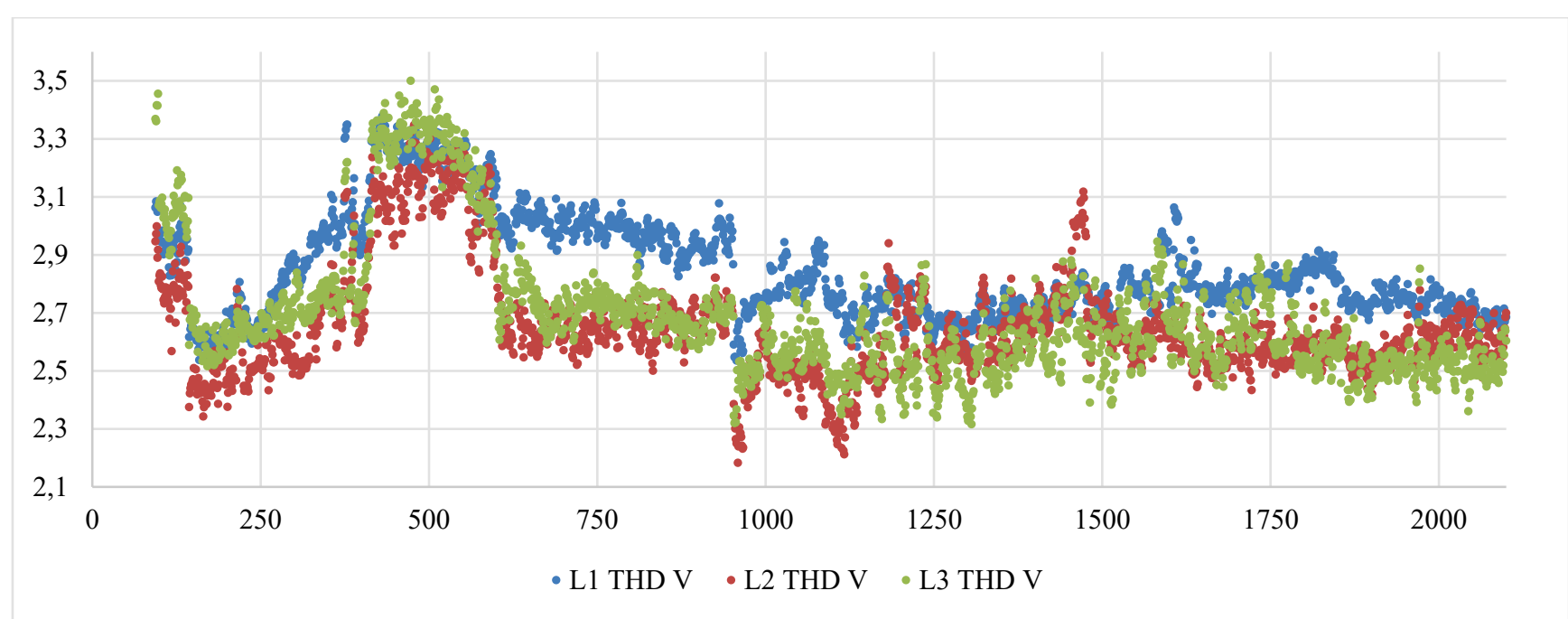

Figure 2 THD results for the passive distribution network - Measurement 2 
In order to confirm or refute THD values in the passive distribution network, the second measurement was performed in a completely different distribution network, geographically and electrically very far, with a denser sampling time, as presented in Fig. 2 with 2100 10-minute sample values.

The THD values of the second measurement confirm the values of the first measurement since the maximal THD in the observed period was $3,5 \%$, the minimal THD value was $2,183 \%$ and the average value was $2,72 \%$ as presented in Fig. 2. In the second case, the THD value is satisfactory regarding EN 50160. According to PQ measurements in typical household residential customers were modelled regarding harmonic influence.

In the second passive distribution network measurement scenario, dominating harmonics were the $5^{\text {th }}$ with the average value of $2,115 \%, 3^{\text {rd }}$ with the average value of $1,268 \%, 7^{\text {th }}$ with the average value of $1,040 \%, 9^{\text {th }}$ with the average value of $0,612 \%$ and $15^{\text {th }}$ with the average value of $0,518 \%$.

\section{DISTRIBUTED GENERATION HARMONIC INFLUENCE}

DG can be based on different energy sources and technologies; however, the definition implies distribution network connection [20]. As presented in the previous chapter, a distribution network without DG already has a harmonic feature and additional DG influence needs to be evaluated. The THD influence of PV based DG was systematically analysed by $\mathrm{Du}$ et al. [11] whose considerations coincide with findings of this research regarding the various influences during different operating conditions. PV systems at lower insolation levels can significantly dispatch distorted current in the network, while overall THD in PCC of PV power plant is generally significantly lower. Precisely, it is within the limits pursuant to EN 50160, during nominal insolation, as will be presented in this paper. Lower insolation levels correspond to marginal operating conditions observed by this paper and nominal operating conditions observed imply nominal insolation levels.

Similar THD influence and distorted current result for a PV power plant can be found in [8-10, 21-27]. Generally, it can be concluded that the overall PV contribution to the total system THD is less than $2 \%$ and never exceeds the value of $4 \%$ on the PCC. However, not all PV power plants in the system will have the same harmonic influence and each power plant should be devoted enough attention to evaluate its harmonic influence since some researches indicate that, in some cases, THD in PCC can be significantly higher depending on local network conditions and marginal operating conditions [27]. The majority of harmonic influence considerations described in the literature were made on one PV system basis. The evaluation of the increased number of inverter-based DG influence on a complete, in that case an active one, distribution network is to be made.

Realistic THD influence among the individual components of the distribution system with the different impedance characteristics and different harmonic sources, including synchronous generators based DG, has to be properly addressed in order to determine the PQ of an active distribution network. This paper seeks to provide information about PQ in a completely ADN by modelling significant number of various types DGs and harmonic interaction simulation.

Synchronous generator based DG, although generally accepted to provide an ideal sinusoidal waveform, is also a voltage harmonic source due to flux linkage [15, 28-30]. The measurements done for the purpose of this paper confirm the PQ feature of synchronous generator observed in literature. Despite this, a synchronous machine based DG is considered to be PQ favourable [31, 32].

\subsection{PV PQ Measurements and Modelling}

Based on the EN 50160 guidelines, PQ measurements for PV power plants were performed on two $10 \mathrm{~kW}$ PV residential power plants in different locations in Croatia, both located on a residential sloped rooftop. The first system is composed of $44 \mathrm{c}-\mathrm{Si} \mathrm{PV}$ modules configured in two strings of 17 modules and one string of 10 modules (rated power of each module is $240 \mathrm{~W}$ ) and a three-phase transfomerless grid-tie inverter with the European efficiency of $97,1 \%$ [33].

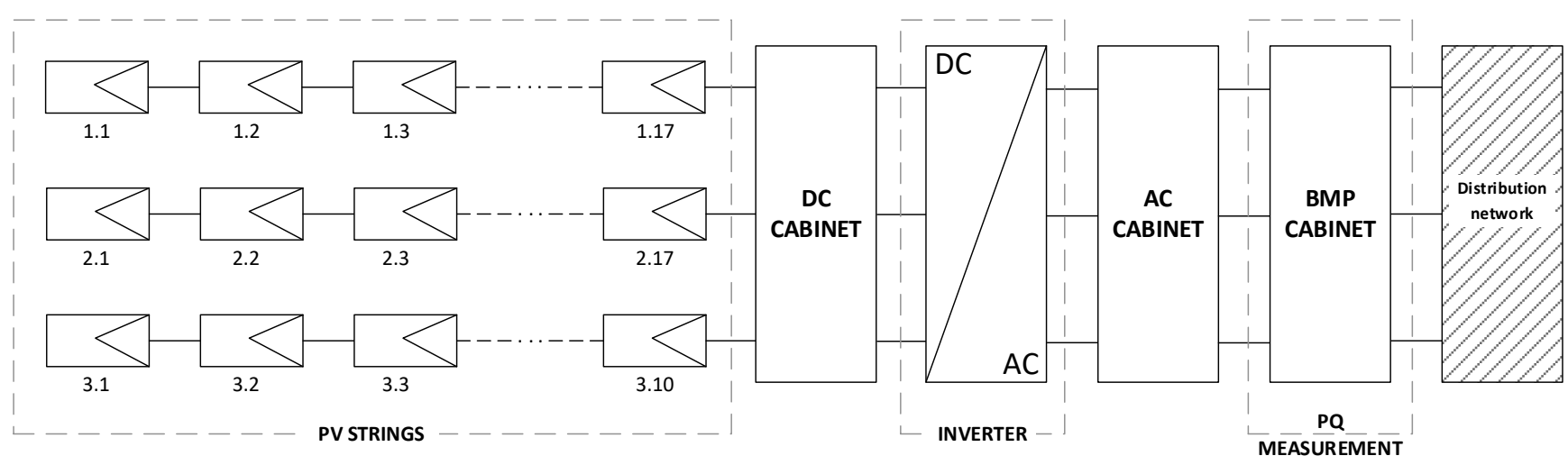

Figure 3 Layout of 10 kW PV System 1

The second system is composed of $42 \mathrm{c}-\mathrm{Si}$ PV modules configured in two strings of 21 modules (rated power of each module is $250 \mathrm{~W}$ ) and with a three-phase transfomerless grid-tie inverter (different manufacturer than in the first system) with the European efficiency of $97,6 \%$ [34]. Each measurement was performed at the point where the PV power plant connects to the distribution network which, in Croatian terms, is the electrical cabinet 
of billing and metering point (BMP cabinet) as presented for case 1 by Fig. 3. BMP cabinet represents PCC for each PV power plant. During the measurement process, a current signal dispatched from the PV system towards the grid is continuously recorded with all the harmonic content so the current harmonics can be evaluated and analysed.

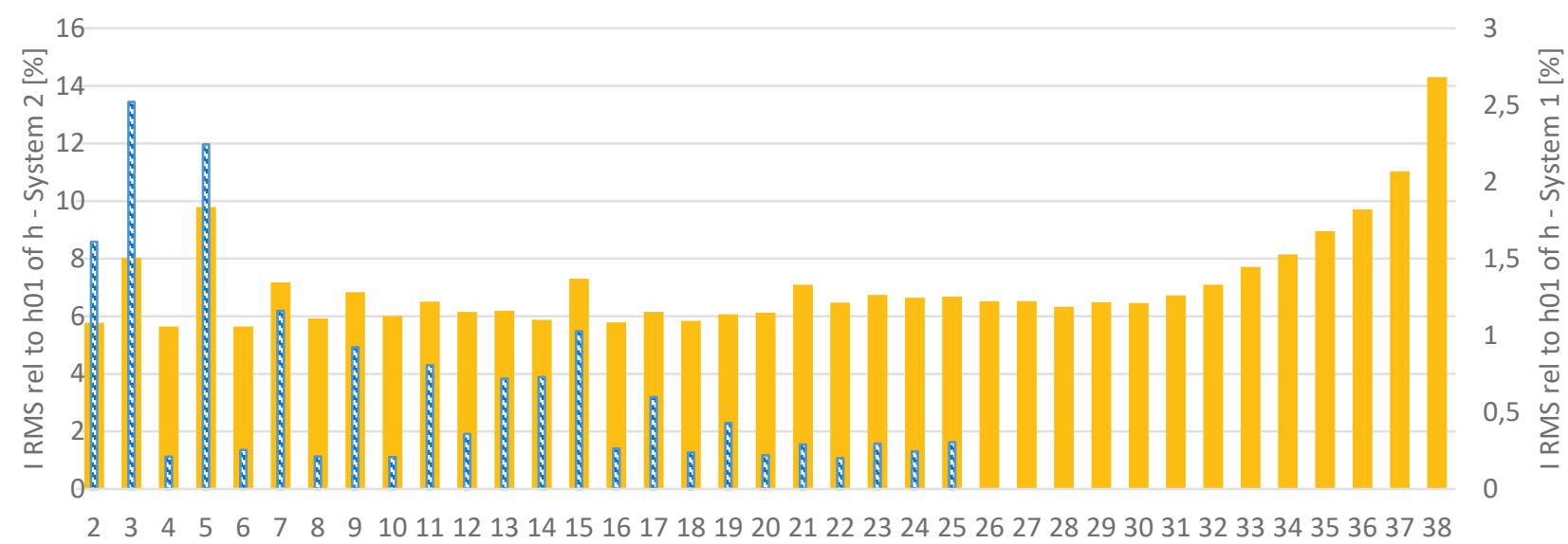

Harmonic $h$

- I RMS rel to h01 of h [\%] - System 2 (

Figure 4 Identified current harmonics for the observed PV systems

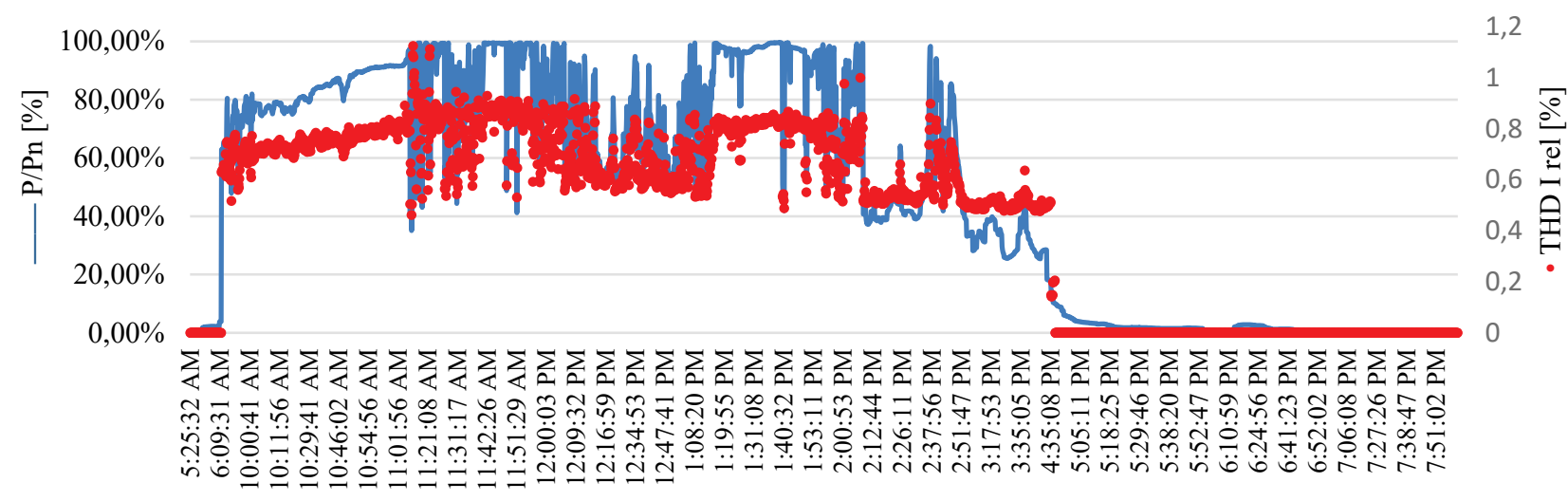

Time $[\mathrm{h}]$
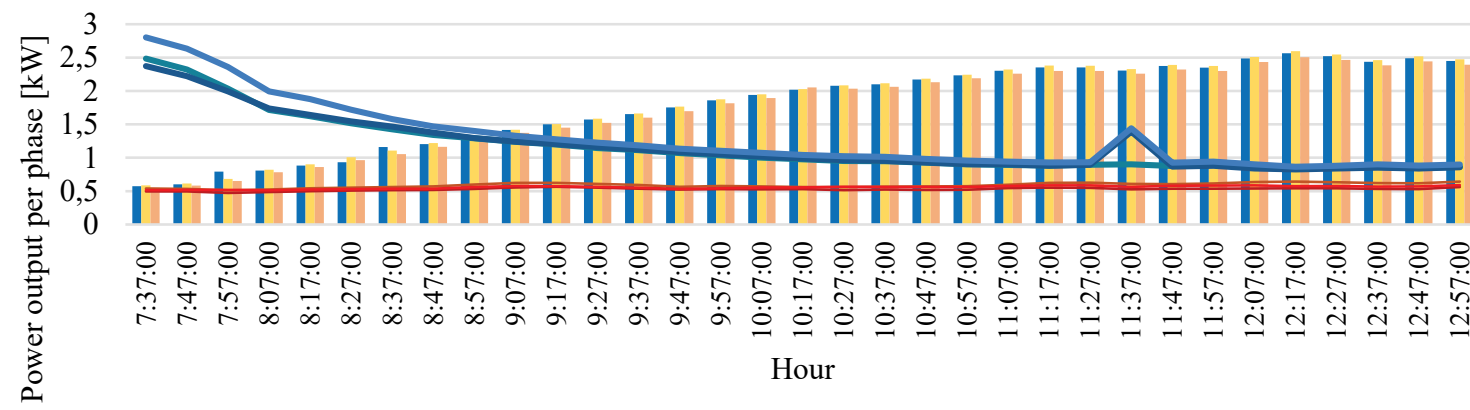

$12,00 \%$

$10,00 \%$ के

$8,00 \%$

$6,00 \%$

$4,00 \%$

$2,00 \%$

$0,00 \%$

1.

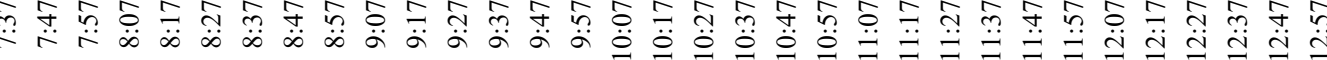

Hour

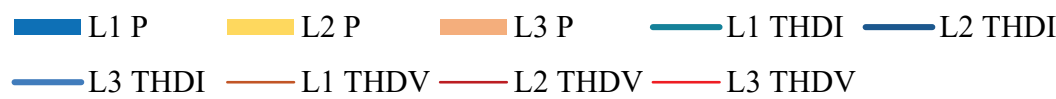

Figure 5 Daily diagram of energy production and THDI generation for a nominal operating conditions (a); Half-day detailed per-phase overview of PV system production, THDI and THDV (b)

As illustrated in Fig. 4, the spectral analysis of the measured current signal from the PV power plant (for PV system 1 and PV system 2) shows all of the identified harmonics during the observed period.

Different results correspond to different inverter manufacturer [35], rooftop orientation and different insolation levels pointing out the differences in nominal and marginal operation conditions. Low insolation conditions result in a high harmonic output of the PV system [11, 12, 23]. By the end of March 2017, the observed network included two $10 \mathrm{~kW}$ PV power plants. Harmonic influence during the nominal operating 
conditions is given as an example for the second observed PV system in Fig. 5a. A more detailed description for a part of a day and per each phase is provided in Fig. $5 \mathrm{~b}$.

A PV system harmonic modelling principle is a set of current sources [36] resulting in production output current with all harmonic components.

The calculated values for each harmonic current are utilized for the modelling PV system as a current source with multiple integer harmonic components according to IEC 61000 [37]. The average values of each harmonic component during observation time $T$ are calculated by the expression:

$$
I_{h \text { rel to } h 01}(t)=\frac{1}{T-1} \int_{0}^{T} \frac{\left|i_{h}(t)\right|}{|i|} \mathrm{d} t
$$

\subsection{Synchronous Machine based DG PQ Measurements and Modelling}

According to the Croatian Chamber of Economy, Croatia had 14 biogas power plants in March 2015. There is no recent official data; however, it is estimated that the number of biogas power plants increased to 20 by the end of 2016. In this paper, a biogas power plant represents a synchronous machine based DG since it represents the most common DG type with the averages of $1 \mathrm{MW}$ installed power and nominal THD value of 1,5\% [38]. There are two active connection requests in the observed distribution network for biomass gasification power plants that utilize the same synchronous generator as waste-based biogas power plants. According to the Croatian law and regulation documents, each DG needs to fulfil network parallel operation requirements which are tested in a trial operation period [39].

During that period, the PQ analysis is conducted on the observed power plant's medium voltage side, which represents the PCC for a small scale DG. The spectral analysis of the measured voltage signal from SM based DG with all identified harmonics during the observed period is presented in Fig. 6. The harmonic analysis results correspond to the results presented in scientific and technical literature. Power production from the gas-based $\mathrm{DG}$ is considered to be constant because it is driven by economic criteria with a significant fuel supply.

Pursuant to IEC 61000, the harmonic model of SM is taken as a Thevenin equivalent, in harmonic voltage amplitude contribution of the total per-unit voltage of the observed SM [37].

\section{ACTIVE DISTRIBUTION NETWORK MODELLING AND SIMULATION}

For the purpose of this paper, a real distribution network consisting of 2 high voltage $110 \mathrm{kV}$ terminals, 4 medium voltage (MV) $35 \mathrm{kV}$ terminals, $37 \mathrm{MV} 10 \mathrm{kV}$ terminals and 294 low voltage (LV) $0,4 \mathrm{kV}$ terminals was accurately modelled in DIgSILENT Power Factory software package. The observed system is the distribution network of a small town in the Eastern part of Croatia consisting of 261 modelled residential consumers with the average three-phase rated power of $11,04 \mathrm{~kW}$ [40]. In addition to residential consumers, commercial and industrial consumers were modelled on adequate mediumvoltage buses resulting in the total load of 3,009 MW.

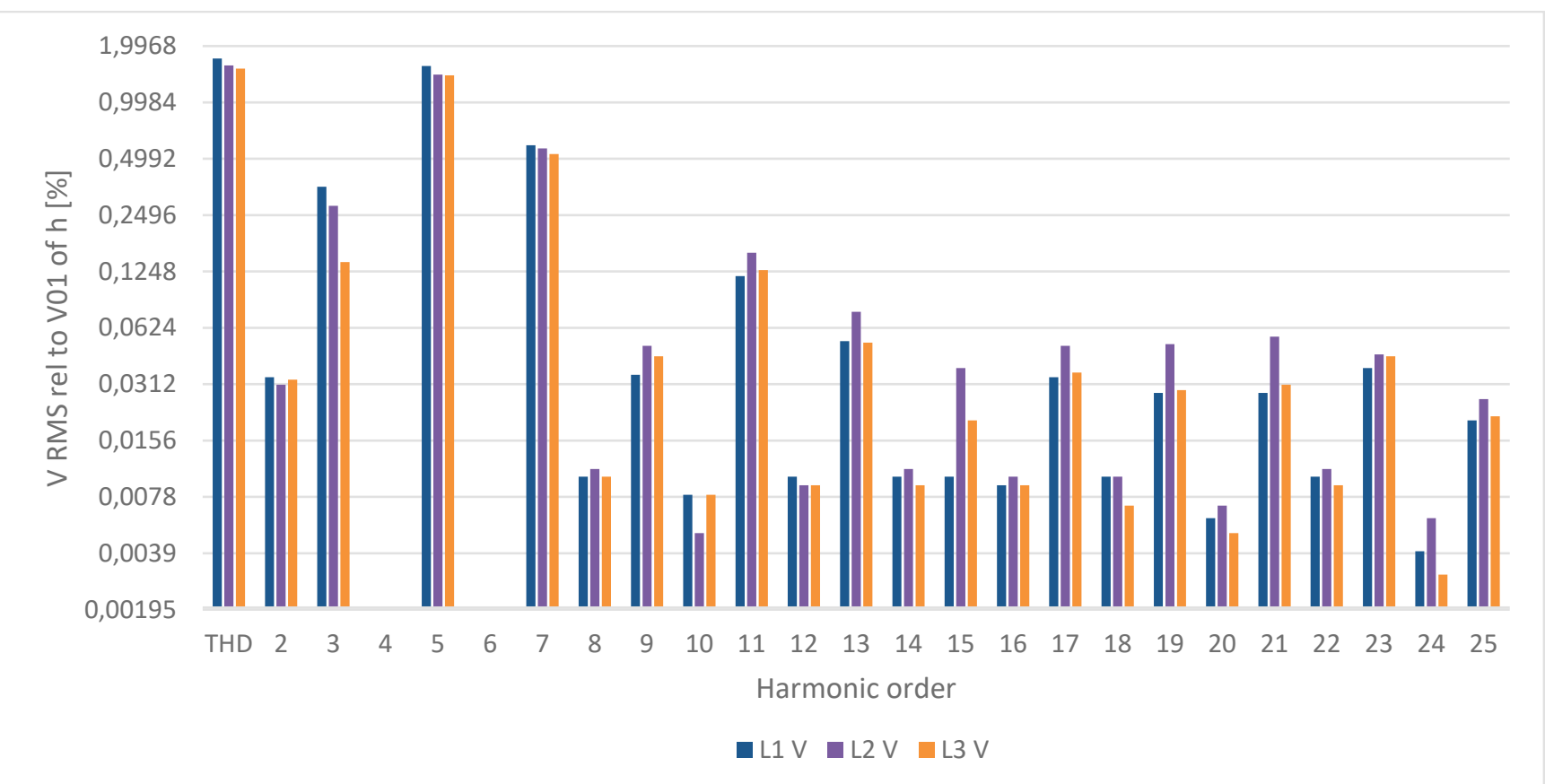

Figure 6 Identified voltage harmonics for the observed SM based DG

The initial considerations for this research were based on the increasing number of requests for small scale PV power plants connection along with DG expansion due to a favourable feed-in tariff system [41]. A common approach for distribution system modelling involves medium voltage levels design and low voltage feeder estimation based on the power measurements, where applicable, or power approximations by determining load equivalents. 
However, such approach cannot provide a complete idea of harmonic propagation through the low voltage levels with sensitive network characteristics such as line parameters - a problem comprehensively described in [42] and in [43] for a transmission system.
An underlying assumption of the active distribution network is the possibility of self-sufficiency and an island operation mode [44-46] implying DG expansion on every voltage level.

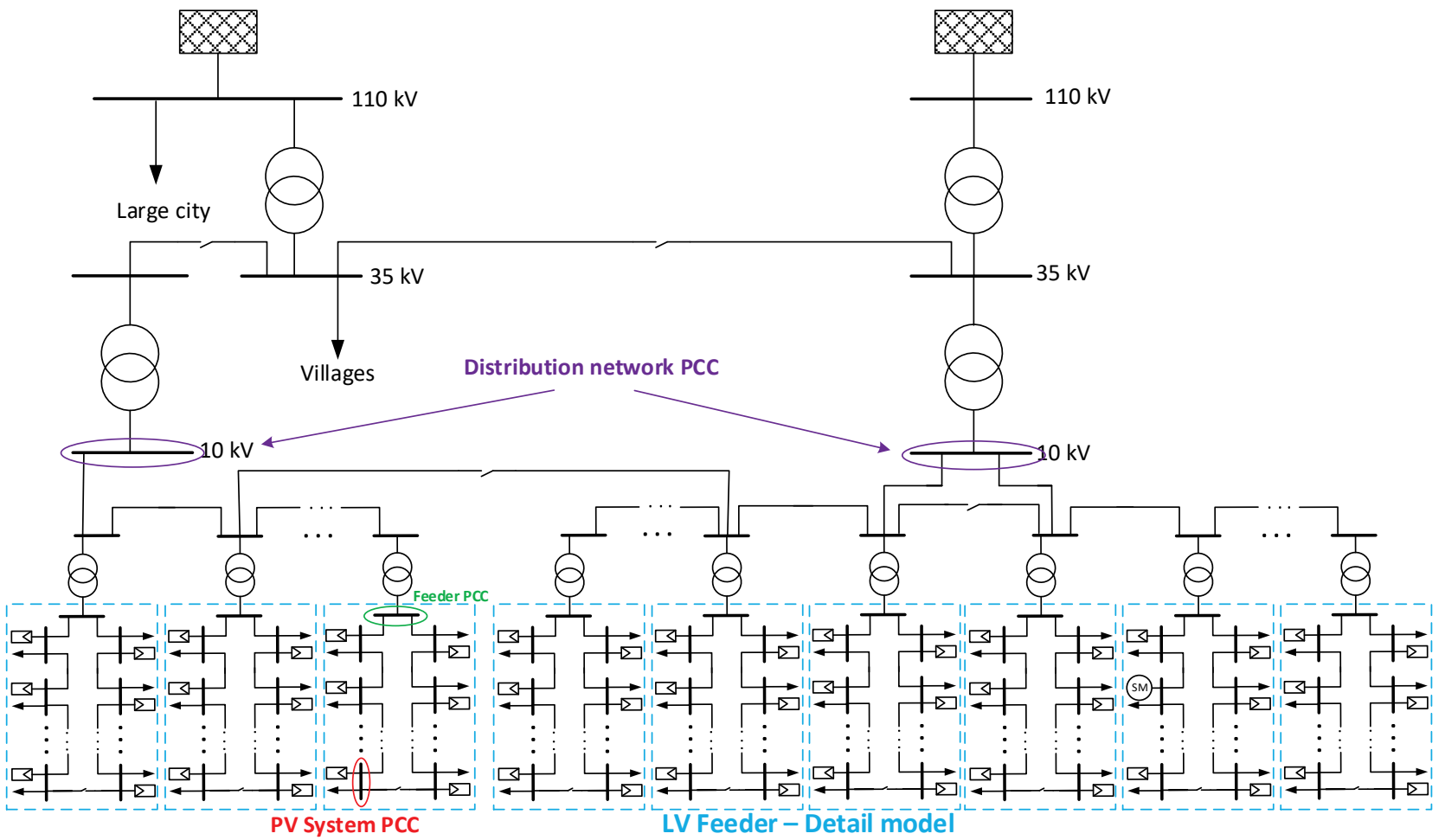

Figure 7 Principal scheme of the observed power system

For the purpose of this research, four cases are considered considering DG expansion scenarios:

Case 1 - existing DG harmonic influence consisting of 1 SM based DG and 2 PV systems in the predefined terminals;

Case 2 - the first stage DG expansion scenario consisting of $2 \mathrm{SM}$ based DGs in the predefined terminals and $30 \%$ of random households being implemented by a PV system;

Case 3 - the second stage expansion scenario consisting of $2 \mathrm{SM}$ based DGs in the predefined terminals and $60 \%$ of random households being implemented by a PV system;

Case 4 - the third stage expansion scenario consisting of 2 SM based DGs in the predefined terminals and $100 \%$ of random households being implemented by a PV system, which totals in $261 \mathrm{PV}$ systems.

Additionally, for the control and verification purposes, a separate case which includes PDN only and harmonic data, obtained by household PQ measurement, will be observed. In order to determine the residential PV systems expansion, carried out in Case 2 and Case 3, MATLAB Random Number Generator was used. Randomly selected integer values of residential consumers' bus numbers range from 1 to 261 in a closed interval and depend on the percentage of observed households. It is believed that this approach is the best description of the investing trends and unpredictability of private small-scale investors. The total generation of PV systems in Case 4 is 2,61 MW.
Harmonic influence and overall harmonic propagation is observed on multiple PCCs defined for this project, as presented by Fig. 7 - BMP Cabinet representing PV System PCC, LV side in the transformer station (TS) representing LV feeder PCC, and MV (10kV) side in the parent TS for observing harmonic interaction in the distribution network. Every LV feeder is modelled in detail according to the actual number of connected households, actual consumer load and power factor according to the data provided by the local DSO. Some components of $35 \mathrm{kV}$ network and all of the $10 \mathrm{kV}$ and $0,4 \mathrm{kV}$ network components of the observed system represent the considered feeder (or the distribution network) in this paper.

The transformer stations are configured in a model as they are configured in a real system (pursuant to the means of good practice) in order to avoid long LV feeders with many consumers and dividing large distribution areas on multiple feeders when necessary. Transformers rated powers are adopted from the real system where they are determined by a number of consumers. The rated power of the feeder transformers are in the interval from $100 \mathrm{kVA}$ to $630 \mathrm{kVA}$.

The voltage waveforms and spectrum results at the observed buses, described in the next chapter, can be derived from a linear circuit theorem the superposition principle [42]. Taking into account the voltage definition as the sum of weighted independent harmonic currents, it defines a harmonic transfer through impedance between buses $i$ and $j$ with the following equation: 


$$
V_{i}=\sum_{j=1}^{n} Z_{i j} I_{j}
$$

The harmonic load flow is executed according to IEC 61000-3-6 for positive sequence and negative sequence components [37], [47] and for all frequencies appearing in the system. THD calculations are based on fundamental frequency values, as defined by IEEE standards [37], with harmonic sources modelled according to IEC 61000.

Table 1 Simulation results overview
\begin{tabular}{|l|c|c|c|c|c|}
\hline & PDN & Case 1 & Case 2 & Case 3 & Case 4 \\
\hline PV System PCC THD max (\%) & 1,2023 & 1,4551 & 7,9392 & 7,9707 & 8,1254 \\
\hline PV System PCC THD min (\%) & 0,6636 & 0,8465 & 1,0697 & 1,3140 & 1,5495 \\
\hline Feeder PCC THD max (\%) & 1,3477 & 1,3536 & 3,5593 & 3,6281 & 3,8721 \\
\hline Feeder PCC THD min (\%) & 0,5208 & 0,5476 & 0,9247 & 1,1092 & 1,2485 \\
\hline Distribution network PCC THD (\%) & 0,5145 & 0,5413 & 0,8963 & 1,0900 & 1,2534 \\
\hline Average THD Value (\%) & 1,0885 & 1,0985 & 1,8154 & 2,1145 & 2,4294 \\
\hline
\end{tabular}

\section{$5 \quad$ RESULTS AND DISCUSSIONS}

After a series of the performed simulations, an increase in DG power plants and their influence on THD in nominal operating conditions for the observed network can be clarified. The results of each simulation case are presented in Tab. 1, where the PV System PCC THD represents a THD level for a bus with an active PV system; the feeder PCC THD represents a THD level for a feeder bus with the highest and the smallest THD values respectively; the distribution network PCC THD represents a distinction bus between the medium and the high voltage level. In PDN case, the PV System PCC THD represents the maximum and the minimum THD values of passive LV buses. The average THD value represents the mean THD level in the observed system considering all system buses. Since the input data for the harmonic contribution are the average values for each harmonic according to IEC 61000 [37], the simulation results represent the average values in a nominal operating mode. A complete THD values overview for each observed case is presented in Figs. 8-11 where the observed network specifications along with THD values for all feeder buses are presented.

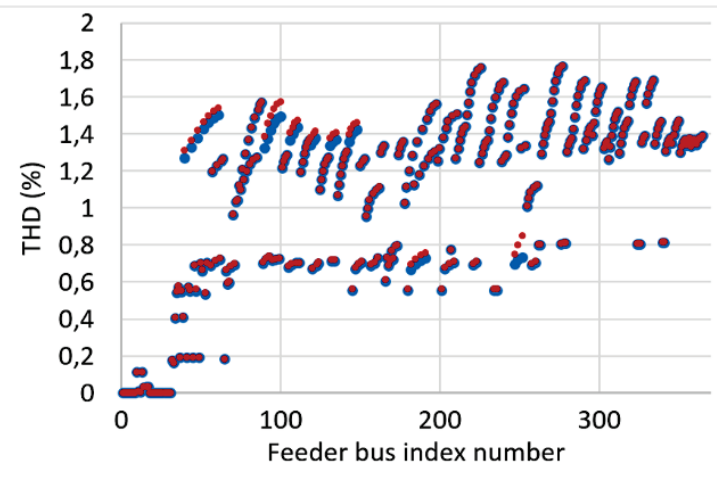

- Nominal operation THD \% - Marginal operation THD \%

Figure 8 THD results for Case 1

The simulation results indicate that the complete development of an active distribution network, in which every household installs a PV System, may lead to local THD problems which may not exist in the entire system. The harmonic influence of one PV system is $1,54 \%$ and it does not change the overall THD in the system remarkably; however, increasing the number of domestic PV systems and $\mathrm{SM}$ based DG, the total harmonic contribution can become a problem at some point in the network expansion process depending on the network topology and expansion scenarios.

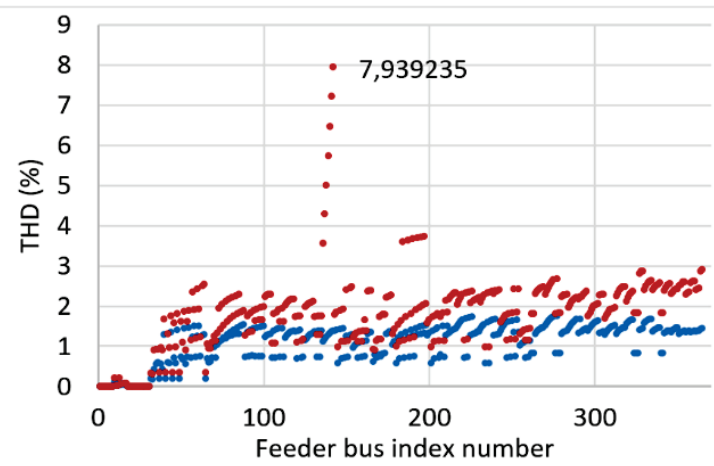

- Nominal operation THD \% • Marginal operation THD \%

Figure 9 THD Results for Case 2

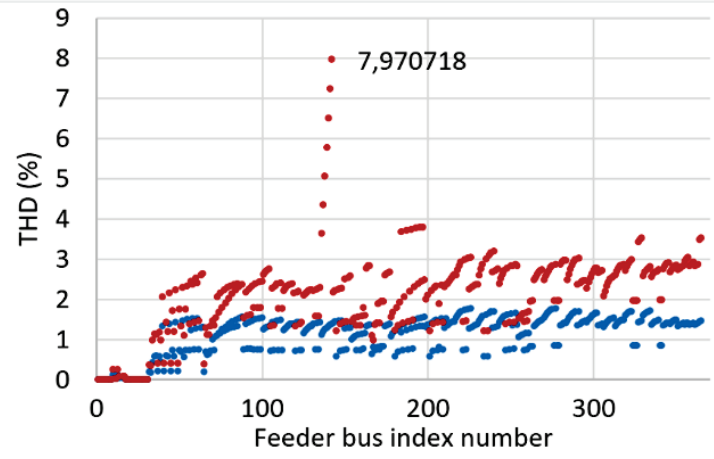

- Nominal operation THD \% • Marginal operation THD \%

Figure 10 THD Results for Case 3

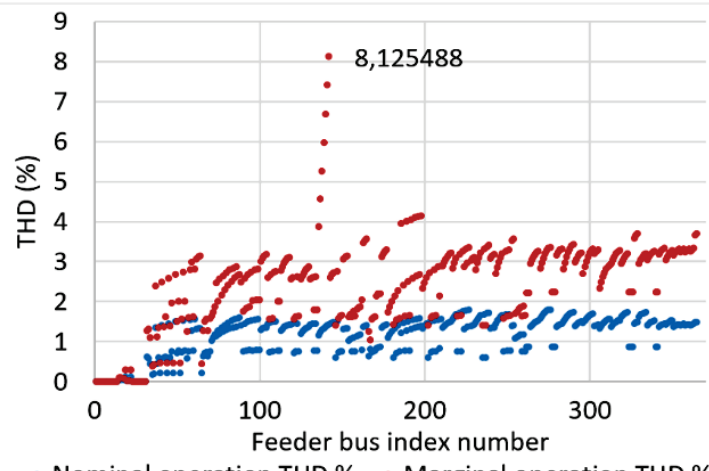

- Nominal operation THD \% • Marginal operation THD \%

Figure $11 \mathrm{THD}$ results for Case 4 

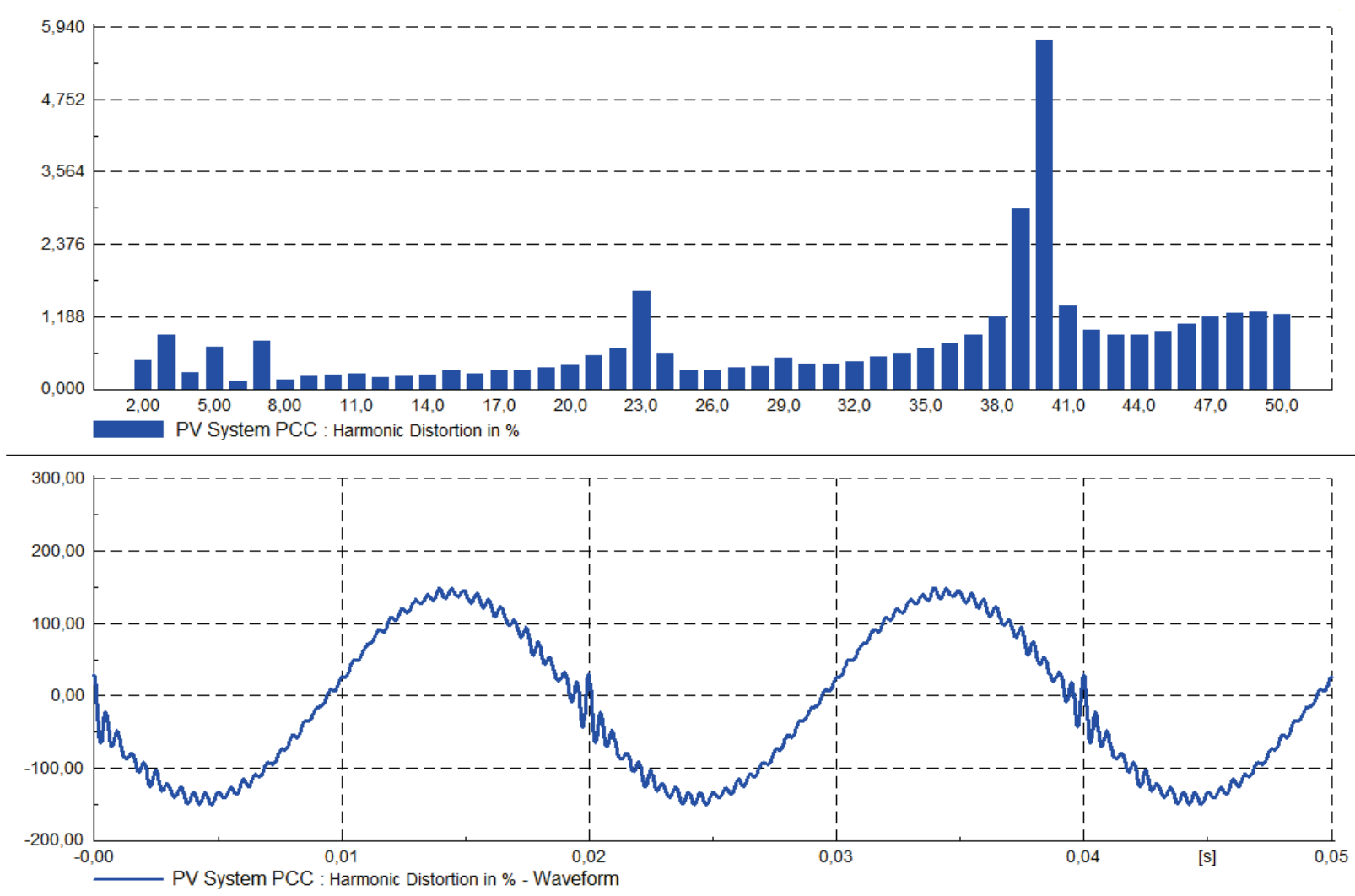

Figure 12 Harmonic spectrum and sinusoidal waveform for PV system PCC with the highest THD value
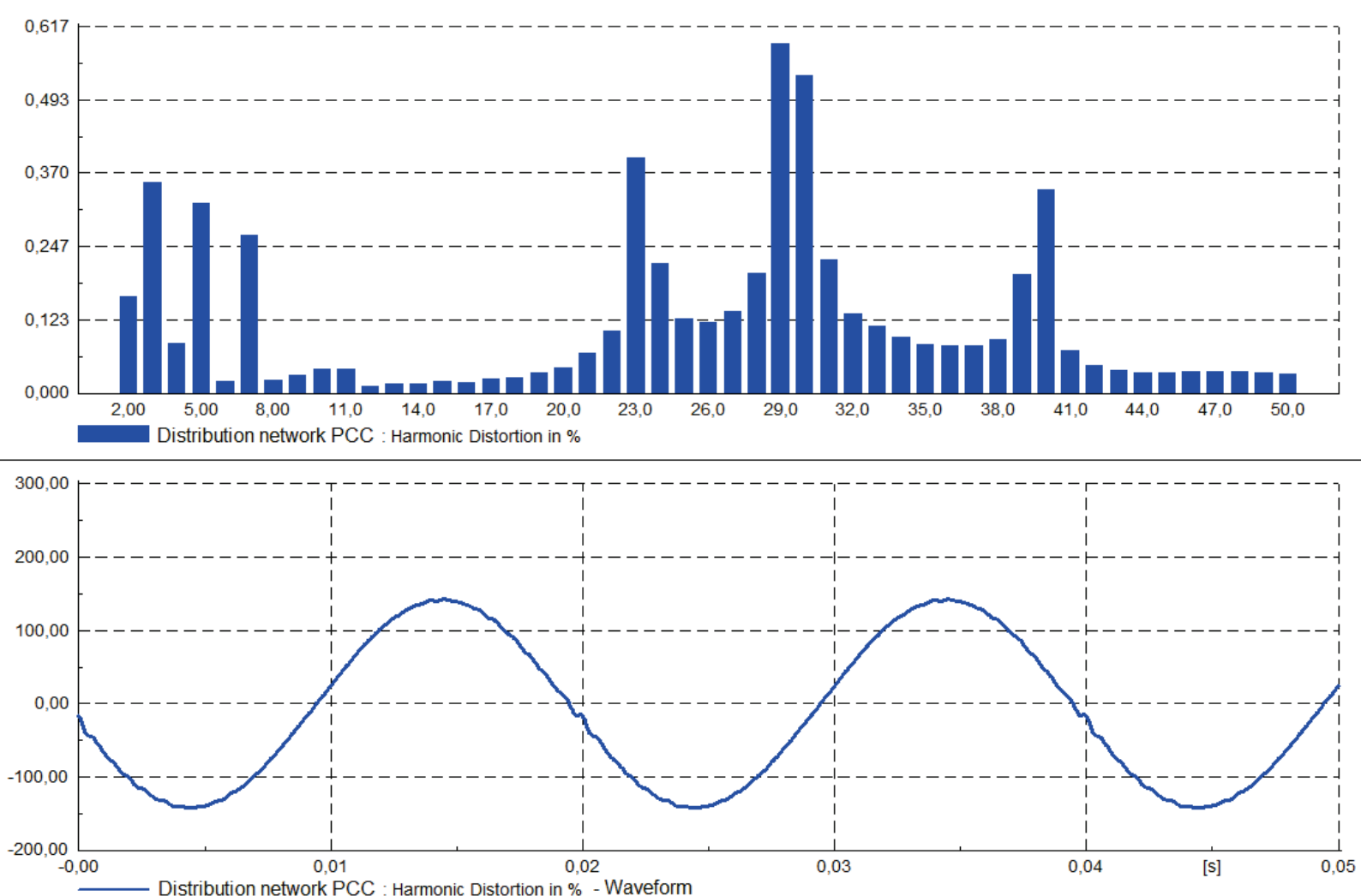

Figure 13 Harmonic spectrum and sinusoidal waveform for ADN PCC

It is important to notice that only one bus of the observed system had the THD value over $8 \%$ - a limit defined by EN 50160 [14]. The second highest THD value was $7,4031 \%$. The local THD violation can be attributed to a specific network topology, a long radial feeder typical for rural distribution networks with long overhead and cable lines that may cause resonance.

The highest THD value is observed at the end of the longest feeder from TS with maximal short-circuit power in the observed network. A voltage waveform for a LV PV 
System PCC with the highest THD value in Case 4 is given in Fig. 12.

From the analysis of the THD values and the location of the buses with the highest THD levels, it can be concluded that the allocation of the PV system strongly correlates with the harmonic influence since the propagation occurs through the different impedance.

The topic of this research is the ADN and its impact on the rest of the power system, therefore the harmonic spectrum and waveform in the distribution network PCC, that represents the ADN PCC, is presented in Fig. 13.

The THD level on a HV side of the ADN PCC after transformation to a $35 \mathrm{kV}$ voltage level with Dyn5 transformer is $0,453 \%$ with the following spectrum values: $2^{\text {nd }}$ harmonic $-0,063 \% ; 3^{\text {rd }}$ harmonic $-0,134 \% ; 4^{\text {th }}$ harmonic $-0,033 \% ; 5^{\text {th }}$ harmonic $-0,102 \% ; 7^{\text {th }}$ harmonic $-0,093 \% ; 9^{\text {th }}$ harmonic $-0,011 \%$ and significant value of $23^{\text {rd }}$ harmonic $-0,238 \%$.

\section{CONCLUSION}

The impact of DG from various sources on the occurrences and the propagation of harmonics in ADN was carried out by detailed modelling of the entire distribution network and a distribution area of a small town in the eastern part of Croatia. The harmonic generation of different DG technologies was obtained by multiple PQ measurements with class "A" device resulting in different harmonic sources identification according to IEC 61000.

Additionally, several passive nodes were selected for PQ measurements resulting in THD evaluation of the passive distribution network and consumer contribution identification so the active distribution network development and DG influence can be evaluated. According to scientific literature, PV systems were modelled as harmonic current sources and synchronous machines were modelled as voltage harmonic sources. Small town distribution network consisting of 261 residential customers was modelled and four DG expansion scenarios were considered.

The results obtained by extensive simulations pointed to the necessity for a detailed harmonic impact evaluation of each potential DG and ADN in total. The network topology has proven to be a key factor in harmonics propagation and THD level trends - an idea recognized by scientific literature and confirmed with the simulation results.

A general conclusion may indicate that the increased DG penetration level does not affect the global THD in the system so the limits, given by the standard EN 50160, will be violated, but the local standard violations are possible, which depends on multiple factors such as network topology, probabilistic harmonic voltages, current occurrences and general conditions of the observed power system. Further analysis indicated that the local THD issues did not extend to the parent network or to the neighbouring feeders so the PQ issue identified locally can be addressed on the site.

\section{REFERENCES}

[1] European Parliament. (2003). Directive 2003/54/EC of the European Parliament and of the Council of 26 June 2003 concerning common rules for the internal market in electricity and repealing Directive 96/92/EC THE. Official Journal of the European Union, 2002(176), 37-55. https://doi.org/02003L0054-20110303

[2] Frías, P., Gómez, T., Cossent, R., \& Rivier, J. (2009). Improvements in current European network regulation to facilitate the integration of distributed generation. International Journal of Electrical Power and Energy Systems, 31(9). 445-451. https://doi.org/10.1016/j.jijepes.2009.03.001

[3] Cossent, R., Gómez, T., \& Frías, P. (2009). Towards a future with large penetration of distributed generation: Is the current regulation of electricity distribution ready? Regulatory recommendations under a European perspective. Energy Policy, 37(3), 1145-1155. https://doi.org/10.1016/j.enpol.2008.11.011

[4] Colmenar-Santos, A., Reino-Rio, C., Borge-Diez, D., \& Collado-Fernández, E. (2016). Distributed generation: A review of factors that can contribute most to achieve a scenario of DG units embedded in the new distribution networks. Renewable and Sustainable Energy Reviews, 59, 1130-1148. https://doi.org/10.1016/j.rser.2016.01.023

[5] Ruiz-Romero, S., Colmenar-Santos, A., Mur-Pérez, F., López-Rey, Á. (2014). Integration of distributed generation in the power distribution network: The need for smart grid control systems, communication and equipment for a smart city - Use cases. Renewable and Sustainable Energy Reviews, 38, 223-234. https://doi.org/10.1016/j.rser.2014.05.082

[6] Samra, A. H. \& Islam, K. M. (1995). Harmonic Effects on Synchronous Generators Voltage Regulation. Proceedings IEEE Southeastcon '95. Visualize the Future, 2, 376-380. https://doi.org/10.1109/SECON.1995.513121

[7] Arghandeh, R., Onen, A., Jung, J., \& Broadwater, R. P. (2013). Harmonic interactions of multiple distributed energy resources in power distribution networks. Electric Power Systems Research, 105, 124-133. https://doi.org/10.1016/j.epsr.2013.07.018

[8] Nair, N. \& Jing, L. (2012). Power quality analysis for building integrated PV and micro wind turbine in New Zealand. Energy and Buildings, 58, 302-309. https://doi.org/10.1016/j.enbuild.2012.09.029

[9] Varatharajan, A., Schoettke, S., Meyer, J., \& Abart, A. (2014). Harmonic Emission of Large PV Installations Case Study of a $1 \mathrm{MW}$ Solar Campus. International Conference on Renewable Energies and Power Quality (ICREPQ'14), Cordoba (Spain), 12, 701-706. https://doi.org/10.24084/repqj12.460

[10] Plangklang, B., Thanomsat, N., \& Phuksamak, T. (2016). A verification analysis of power quality and energy yield of a large scale PV rooftop. Energy Reports, 2, 1-7. https://doi.org/10.1016/j.egyr.2015.12.002

[11] Du, Y., Lu, D. D.-C., James, G., \& Cornforth, D. J. (2013). Modeling and analysis of current harmonic distortion from grid connected PV inverters under different operating conditions. Solar Energy, 94, 182-194. https://doi.org/10.1016/j.solener.2013.05.010

[12] Fekete, K., Klaic, Z., \& Majdandzic, L. (2012). Expansion of the residential photovoltaic systems and its harmonic impact on the distribution grid. Renewable Energy, 43, 140148. https://doi.org/10.1016/j.renene.2011.11.026

[13] Hernández, J. C., Ortega, M. J., De La Cruz, J., \& Vera, D. (2011). Guidelines for the technical assessment of harmonic, flicker and unbalance emission limits for PV-distributed generation. Electric Power Systems Research, 81(7), 12471257. https://doi.org/10.1016/j.epsr.2011.03.012

[14] (2005). CENELEC, EN 50160, 1-20.

[15] Masoum, M. A. S. \& Fuchs, E. F. (2015). Power Quality in Power Systems and Electrical Machines, Second Edi., Academic Press. 
[16] Senra, R., Boaventura, W. C., \& Mendes, E. M. A. M. (2017). Assessment of the harmonic currents generated by single-phase nonlinear loads. Electric Power Systems Research, 147, 272-279. https://doi.org/10.1016/j.epsr.2017.02.028

[17] Gil-De-Castro, A., Rönnberg, S. K., Bollen, M. H. J., \& Moreno-Mu-oz, A. (2014). Study on harmonic emission of domestic equipment combined with different types of lighting. International Journal of Electrical Power and Energy Systems, 55, 116-127. https://doi.org/10.1016/j.ijepes.2013.09.001

[18] Soliman, S. A. \& Alkandari, A. M. (2011). Power Quality Harmonics Analysis and Real Measurements Data, Chapter 1 - Electric Power Systems Harmonics - Identification and Measurements, InTech.

[19] Stojkov, M., Trupinić, K., \& Nikolovski, S. (2009). Procedure for determination of harmonic distortion along the distribution network. Tehnički vjesnik, 16(4), 19-26,

[20] Luszcz, J. et al., (2015). Power Quality Issues in Distributed Generation, AvE4EvA.

[21] Patsalides, M., Stavrou, A., Efthymiou, V., \& Georghiou, G. E. (2012). Towards the establishment of maximum PV generation limits due to power quality constraints. International Journal of Electrical Power and Energy Systems, 42(1), 285-298. https://doi.org/10.1016/j.jijepes.2012.03.043

[22] Ortega, M. J., Hernández, J. C., \& García, O. G. (2013). Measurement and assessment of power quality characteristics for photovoltaic systems: Harmonics, flicker, unbalance, and slow voltage variations. Electric Power Systems Research, 96, 23-35. https://doi.org/10.1016/j.epsr.2012.11.003

[23] Menti, A., Zacharias, T., \& Milias-Argitis, J. (2011). Harmonic distortion assessment for a single-phase gridconnected photovoltaic system. Renewable Energy, 36(1), 360-368. https://doi.org/10.1016/j.renene.2010.07.001

[24] Urbanetz, J., Braun, P., \& Rüther, R. (2012). Power quality analysis of grid-connected solar photovoltaic generators in Brazil. Energy Conversion and Management, 64, 8-14. https://doi.org/10.1016/j.enconman.2012.05.008

[25] Chang, Z. \& Tao, S. (2013). Power Quality Analysis of Photovoltaic Generation Integrated in User-Side Grid. International Journal of Computer and Electrical Engineering, 5(2), 179-182. https://doi.org/10.7763/IJCEE.2013.V5.690

[26] Görbe, P., Fodor, A., Magyar, A., \& Hangos, K. M. (2014). Experimental study of the nonlinear distortion caused by domestic power plants. Applied Thermal Engineering, 1-6. https://doi.org/10.1016/j.applthermaleng.2014.05.072

[27] Hengsritawat, V., Tayjasanant, T., \& Nimpitiwan, N. (2012). Optimal sizing of photovoltaic distributed generators in a distribution system with consideration of solar radiation and harmonic distortion. International Journal of Electrical Power and Energy Systems, 39(1), 36-47. https://doi.org/10.1016/j.jijepes.2012.01.002

[28] Ludwinek, K. (2014). Influence of DC voltage and current of field winding on induced stator voltages of a salient pole synchronous generator. International Review of Electrical Engineering, 9(1), 62-72.

[29] Zaneta, E., Anton, B., \& Mucha, M. (2006). Harmonic Distortion Produced by Synchronous Generator in ThermalPower Plant. Proceedings of the $6^{\text {th }}$ WSEAS International Conference on Power Systems, 424-428.

[30] Ludwinek, K. \& Siedlarz, A. (2009). Harmonic Distortion Analysis in Armature Currents of Synchronous Machine During Co-Operation with the Power System. Maszyny Elektryczne, 84, 217-223.

[31] Ugranli, F., Karatepe, E., (2013). Multiple-distributed generation planning under load uncertainty and different penetration levels. International Journal of Electrical Power and Energy Systems, 46(1), 132-144. https://doi.org/10.1016/j.jiepes.2012.10.043

[32] Calderaro, V., Milanovic, J. V., Kayikci, M., \& Piccolo, A. (2009). The impact of distributed synchronous generators on quality of electricity supply and transient stability of real distribution network. Electric Power Systems Research, 79(1), 134-143. https://doi.org/10.1016/j.epsr.2008.05.022

[33] KOSTAL, Datenblatt PIKO 10. . KOSTAL Solar Electric, Freiburg i. Br., Germany.

[34] (2016). SMA, Technical Information Efficiency and Derating Sunny Boy / Sunny Boy Storage / Sunny Tripower / Sunny Mini Central., SMA Solar Technology AG, Niestetal, Germany.

[35] Barote, L. \& Marinescu, C. (2014). Software method for harmonic content evaluation of grid connected converters from distributed power generation systems. Energy, 66, 401412. https://doi.org/10.1016/j.energy.2013.12.050

[36] (2001). Task Force on Harmonics Modeling and Simulation, I. P. H. W. G., Characteristics and modeling of harmonic sources-power electronic devices. IEEE Transactions on Power Delivery, 16(4), 791-800. https://doi.org/10.1109/61.956771

[37] (2014). DIgSILENT GmbH., DIgSILENT PowerFactory 15 User Manual, Online Edi., Gomaringen, Germany: DIgSILENT GmbH.

[38] (2012). AB Energy, Technical Description Genset JGS 320 GS-B.L., GE, 1-11.

[39] Glavaš, K. \& Zdunić, M. (2008). Connection of the Small Power Plants to Distribution Grid and Comparison with EU Regulation. CIRED - Croatian Committee, $1^{\text {st }}$ Conference, SO4-01, 1-7.

[40] (2015). HEP - Croatian Distribution System Operator, The request for issuing preliminary energy consent.

[41] (2017). The Government of The Republic of Croatia, The Tariff System for the Production of Electricity from Renewable Energy Sources and Cogeneration (Official Gazette 63/2012, 121/2013, 144/2013), The Government of the Republic of Croatia, Zagreb, Croatia.

[42] Baghzouz, Y., Burch, R. F., Capasso, A., Cavallini, A., Emanuel, A. E., Halpin, M., Langella, R., Montanari, G., Olejniczak, K. J., Ribeiro, P., Rios-Marcuello, S., Ruggiero, F., Thallam, R., Testa, A., \& Verde, P. (2002). Time-varying harmonics: Part II - Harmonic summation and propagation. IEEE Transactions on Power Delivery, 17(1), 279-285. https://doi.org/10.1109/61.974219

[43] Watson, N. R. \& Arrillaga, J. (2003). Harmonics in large systems. Electric Power Systems Research, 66(1), 15-29. https://doi.org/10.1016/S0378-7796(03)00068-3

[44] Bayod-Rújula, A. A. (2009). Future development of the electricity systems with distributed generation. Energy, 34(3), 377-383. https://doi.org/10.1016/j.energy.2008.12.008

[45] Lopes, J. A. P., Hatziargyriou, N., Mutale, J., Djapic, P., \& Jenkins, N. (2007). Integrating distributed generation into electric power systems: A review of drivers, challenges and opportunities. Electric Power Systems Research, 77(9), 1189-1203. https://doi.org/10.1016/j.epsr.2006.08.016

[46] Chowdhury, S. P., Chowdhury, S. P., \& Crossley, P. A. (2011). UK scenario of islanded operation of active distribution networks with renewable distributed generators. International Journal of Electrical Power and Energy Systems, 33(7), 1251-1255. https://doi.org/10.1016/j.ijepes.2011.01.004

[47] Kamenka, A. (2014). Six tough topics about harmonic distortion and Power Quality indices in electric power systems. Schaffner Group, Luterbach, Switzerland. 


\section{Contact information:}

Marko VUKOBRATOVIĆ, MEng

Faculty of Electrical Engineering, Computer Science and Information

Technology Osijek,

Kneza Trpimira 2b, 31000 Osijek, Croatia

E-mail: marko.vukobratovic@ferit.hr

Izv. prof. dr. sc. Predrag MARIĆ

Faculty of Electrical Engineering, Computer Science and Information

Technology Osijek

Kneza Trpimira 2b, 31000 Osijek, Croatia

E-mail: predrag.maric@etfos.hr

Prof. dr. sc. Srete NIKOLOVSKI

Faculty of Electrical Engineering, Computer Science and Information

Technology Osijek,

Kneza Trpimira 2b, 31000 Osijek, Croatia

E-mail: srete.nikolovski@ferit.hr

Doc. dr. sc. Hrvoje GLAVAŠ

Faculty of Electrical Engineering, Computer Science and Information

Technology Osijek,

Kneza Trpimira 2b, 31000 Osijek, Croatia

E-mail: hrvoje.glavas@ferit.hr 